CLINICAL STUDY

\title{
The association between TSH within the reference range and serum lipid concentrations in a population-based study. The HUNT Study
}

\author{
Bjørn O Åsvold ${ }^{1,2}$, Lars J Vatten ${ }^{1}$, Tom I L Nilsen ${ }^{1}$ and Trine Bjøro ${ }^{3}$ \\ ${ }^{1}$ Department of Public Health, Faculty of Medicine, Norwegian University of Science and Technology, N-7489 Trondheim, Norway, ${ }^{2}$ St Olavs Hospital, \\ Trondheim University Hospital, Trondheim, Norway and ${ }^{3}$ Department of Medical Biochemistry, Rikshospitalet-Radiumhospitalet Medical Center, Oslo, \\ Norway \\ (Correspondence should be addressed to L J Vatten; Email: lars.vatten@ntnu.no)
}

\begin{abstract}
Objective: The association between TSH and serum lipids in people with no apparent thyroid disease is insufficiently understood. We have studied the association between normal thyroid function, defined as TSH within the reference range of a general population, and concentrations of serum lipids.

Design: Cross-sectional, population-based study with 30656 individuals without known thyroid disease.

Methods: Using general linear models, we calculated mean concentrations of total serum cholesterol, low-density lipoprotein (LDL) cholesterol, non-high-density lipoprotein (HDL) cholesterol, HDL cholesterol and triglycerides across categories of TSH.

Results: Within the reference range of TSH, there was a linear and significant $(P$ for trend $<0.001)$ increase in total serum cholesterol, LDL cholesterol, non-HDL cholesterol and triglycerides, and a linear decrease $(P$ for trend $<0.001)$ in HDL cholesterol with increasing TSH. Subgroup analyses showed statistically significant associations for all lipids in men above 50 years of age, and for triglycerides in all age groups. For women, associations were statistically significant in all age groups except for HDL cholesterol in women below 50 years of age. The associations with triglycerides and HDL cholesterol were stronger among overweight than normal weight individuals.

Conclusions: Within the range of TSH that is considered clinically normal, we found that increasing level of TSH was associated with less favourable lipid concentrations. The association with serum lipids was linear across the entire reference range of TSH.
\end{abstract}

European Journal of Endocrinology 156 181-186

\section{Introduction}

Hypothyroidism is often accompanied by serum lipid concentrations that are associated with increased risk of cardiovascular disease (1-3). Subclinical hypothyroidism, characterised by thyroid hormones within the reference range combined with elevated Thyrotrophin (TSH), may also be associated with unfavourable serum lipids, especially if TSH is higher than $10 \mathrm{mU} / \mathrm{l}$ (4). Further, thyroxine treatment of subclinically hypothyroid individuals may reduce total serum cholesterol and low-density lipoprotein (LDL) cholesterol (5-7). Some small studies have shown that serum lipids may also be altered within the range of thyroid function that is considered clinically normal. Evidence from two studies suggests that TSH within the reference range may be positively associated with total serum cholesterol (8) and LDL cholesterol (9), and negatively associated with high-density lipoprotein (HDL) cholesterol (9). It has also been shown that total serum cholesterol and LDL cholesterol were reduced after thyroxine treatment in individuals with TSH in the upper part of the reference range (10).

There is a lack of population-based studies of the association between TSH and serum lipid concentrations. In this study of more than 30000 individuals from the general population, we therefore examined the association between TSH within the reference range and total serum cholesterol, LDL cholesterol, non-HDL cholesterol, HDL cholesterol and triglycerides. We also studied the association with lipid levels for TSH outside the reference range.

\section{Subjects and methods}

Between 1995 and 1997, all inhabitants 20 years and older in Nord-Trøndelag County in Norway were invited to participate in the HUNT Study. A total of 92936 individuals were eligible to participate, and 66140 $(71.2 \%)$ attended. The study has been described in detail elsewhere (11). Briefly, the participants were asked to 
complete a self-administered questionnaire which included questions about thyroid disease. They were asked if they had ever had hyperthyroidism, hypothyroidism, goitre or disease in the thyroid gland; if they had been under treatment with thyroxine, carbimazole or radioactive iodine or if they had undergone thyroid surgery. Information on health and lifestyle factors was also collected, as well as history of diabetes mellitus, angina pectoris, myocardial infarction and stroke, and information on daily use of medication.

Among other items, clinical measurements included height and weight, and a non-fasting venous serum sample was drawn from each individual. Total serum cholesterol, HDL cholesterol and triglycerides were measured shortly after serum collection. Analysis of TSH was carried out in subsamples of the population, including all women above 40 years of age and $50 \%$ of men above 40 years of age. In addition, TSH was measured in 5\% random samples of men and women 20-40 years of age. In total, 34851 individuals from these samples were selected for TSH analysis. Free thyroxine was measured in people whose TSH was lower than $0.2 \mathrm{mU} / \mathrm{l}$ or higher than $4.0 \mathrm{mU} / \mathrm{l}$.

\section{Laboratory measurements}

Serum concentrations of thyroid stimulating hormone (TSH) and free thyroxine were analysed at the Hormone Laboratory, Aker University Hospital, Oslo, using DELFIA hTSH Ultra (sensitivity $0.03 \mathrm{mU} / \mathrm{l}$ and total analytical variation $<5 \%$ ) and DELFIA-free $\mathrm{T}_{4}$ (total analytical variation $<7 \%$ ) respectively both from Wallac Oy, Turku, Finland. The laboratory reference ranges were $0.2-4.5 \mathrm{mU} / \mathrm{l}$ for TSH and 8-20 pmol/l for free thyroxine. Reference ranges for TSH according to age and sex from this study population have been published previously (12). Based on these results, the reference range for TSH in the present study was defined as $0.50-3.5 \mathrm{mU} / \mathrm{l}$.

Serum lipids were analysed at the Central Laboratory, Levanger Hospital, Nord-Trøndelag, using a Hitachi 911 Autoanalyzer (Hitachi, Mito, Japan), applying reagents from Boehringer Mannheim (Mannheim, Germany). Total serum cholesterol and HDL cholesterol were measured by an enzymatic colorimetric cholesterol esterase method, and HDL cholesterol was measured after precipitation with phosphotungstate and magnesium ions. Triglycerides were also measured with an enzymatic colorimetric method. The day-today coefficients of variation were $1.3-1.9 \%$ for total cholesterol, $2.4 \%$ for HDL cholesterol and $0.7-1.3 \%$ for triglycerides.

LDL cholesterol was calculated using the Friedewald formula: $\mathrm{LDL}$ cholesterol=total serum cholesterol HDL cholesterol - one-fifth of the triglyceride concentration (13). LDL cholesterol was only calculated in participants with triglyceride concentrations lower than $4.5 \mathrm{mmol} / \mathrm{l}$. The non-fasting state of the serum samples suggest that concentrations of triglycerides and LDL cholesterol were not accurately measured. Therefore, we calculated non-HDL cholesterol as the difference between total serum cholesterol and HDL cholesterol. Non-HDL cholesterol incorporates not only LDL cholesterol but also the cholesterol content of other atherogenic lipoproteins (14).

\section{Statistical analyses}

Among the 34851 individuals who were selected for TSH analysis, we excluded 4195 from this study, leaving 30656 individuals for analyses. Reasons for exclusion were invalid TSH or lipid measurements, known thyroid illness and lack of information on age, smoking status or time since last meal.

We studied the associations between TSH and serum lipid levels using general linear models where lipid concentrations were log-transformed due to non-normal distribution. We calculated geometric means of each lipid for six categories of TSH within the reference range of 0.50-3.5 mU/l, in men and women. Using TSH as a continuous variable, we estimated partial-regression coefficients, from which we calculated the percentage change in serum lipid levels per mU/l increase in TSH. Statistical significance was assessed by $P$ values for trend. Adjustments were made for age, smoking status and time since last meal. We assessed whether the association between TSH and lipid level differed according to age group (below 50 years of age, 50-69 years of age and 70 years of age and above). We further explored whether the association between TSH and lipid levels differed between overweight and normal weight individuals, using body mass index (BMI; weight divided by the squared value of height) of $25.0 \mathrm{~kg} / \mathrm{m}^{2}$ as cut-off.

In a separate analysis, we included TSH outside the reference range and studied associations with serum lipids. We calculated geometric means of each lipid for five categories of TSH (less than 0.10, 0.10-0.49, 0.50-3.5 (reference range), 3.6-9.9 and $10.0 \mathrm{mU} / \mathrm{l}$ and higher), with the corresponding 95\% confidence intervals (CI). Specifically, we compared serum lipids for individuals within the reference range of TSH, and individuals with suspected subclinical hypothyroid function, defined as TSH 4.1-9.9 mU/l combined with free thyroxine of $8.0 \mathrm{pmol} / \mathrm{l}$ or higher. In the statistical analysis, we adjusted for sex, age, smoking status and time since last meal.

The data were analysed using the Statistical Package for the Social Sciences (SPSS), version 13.0 for Windows (SPSS Inc., Chicago, IL, USA).

The HUNT Study is a collaborative effort of the Faculty of Medicine, the Norwegian University of Science and Technology, the Norwegian Institute of Public Health and Nord-Trøndelag County Council. The study was approved by the regional committee for medical research ethics and by the Norwegian Data Inspectorate. 
Table 1 Geometric mean of serum lipids ( $\mathrm{mmol} / \mathrm{l}$ ) according to categories of thyroid stimulating hormone (TSH) within the reference range (0.50-3.5 mU/l), in men and women.

\begin{tabular}{|c|c|c|c|c|c|c|}
\hline TSH (mU/l) & $N$ & $\begin{array}{l}\text { Total serum } \\
\text { cholesterol }\end{array}$ & $\begin{array}{c}\text { LDL } \\
\text { cholesterol }^{\mathrm{a}}\end{array}$ & $\begin{array}{c}\text { Non-HDL } \\
\text { cholesterol }\end{array}$ & $\begin{array}{c}\text { HDL } \\
\text { cholesterol }\end{array}$ & Triglycerides \\
\hline \multicolumn{7}{|l|}{ Men } \\
\hline 0.50-0.99 & 1638 & 5.78 & 4.11 & 4.46 & 1.24 & 1.46 \\
\hline $1.00-1.4$ & 2861 & 5.85 & 4.21 & 4.55 & 1.22 & 1.48 \\
\hline $1.5-1.9$ & 2476 & 5.86 & 4.22 & 4.58 & 1.20 & 1.56 \\
\hline $2.0-2.4$ & 1387 & 5.91 & 4.26 & 4.63 & 1.20 & 1.58 \\
\hline $2.5-2.9$ & 739 & 5.96 & 4.29 & 4.68 & 1.19 & 1.65 \\
\hline 3.0-3.5 & 444 & 5.98 & 4.34 & 4.75 & 1.15 & 1.67 \\
\hline$\%$ Change $(95 \% \mathrm{Cl})$ & & $1.4(0.8-1.9)$ & $2.0(1.2-2.8)$ & $2.4(1.7-3.2)$ & $-2.6(-3.5$ to -1.8$)$ & $6.4(4.7-8.2)$ \\
\hline$P$ for trend & & $<0.001$ & $<0.001$ & $<0.001$ & $<0.001$ & $<0.001$ \\
\hline \multicolumn{7}{|l|}{ Women } \\
\hline $0.50-0.99$ & 3231 & 5.92 & 4.06 & 4.35 & 1.45 & 1.31 \\
\hline $1.00-1.4$ & 5014 & 5.95 & 4.08 & 4.38 & 1.45 & 1.33 \\
\hline $1.5-1.9$ & 4556 & 6.00 & 4.08 & 4.38 & 1.45 & 1.33 \\
\hline $2.0-2.4$ & 2796 & 6.00 & 4.14 & 4.46 & 1.42 & 1.39 \\
\hline $2.5-2.9$ & 1591 & 6.02 & 4.17 & 4.47 & 1.42 & 1.37 \\
\hline $3.0-3.5$ & 994 & 6.04 & 4.20 & 4.52 & 1.40 & 1.45 \\
\hline$\%$ Change $(95 \% \mathrm{Cl})$ & & $0.9(0.5-1.3)$ & $1.6(1.0-2.1)$ & $1.7(1.2-2.3)$ & $-1.7(-2.3$ to -1.1$)$ & $3.6(2.5-4.7)$ \\
\hline$P$ for trend & & $<0.001$ & $<0.001$ & $<0.001$ & $<0.001$ & $<0.001$ \\
\hline
\end{tabular}

Adjusted for age, smoking status and time since last meal. \% Change, percentage change in serum lipids per mU/l increase in TSH.

aLDL cholesterol was calculated only if serum triglyceride concentrations were lower than $4.5 \mathrm{mmol} / \mathrm{l}$.

\section{Results}

Table 1 shows the association between TSH within the reference range and concentrations of serum lipids. In both men and women, there was a consistent and significant increase in concentrations of total serum cholesterol, LDL cholesterol, non-HDL cholesterol and triglycerides, with increasing concentration of TSH within the reference range of $0.50-3.5 \mathrm{mU} / \mathrm{l}$. There was also a consistent reduction in HDL cholesterol with increasing TSH. These estimates were adjusted for age, smoking status and time since last meal. Additional adjustment for daily use of medication, month of serum collection and prevalence of diabetes mellitus, angina pectoris, myocardial infarction or stroke did not

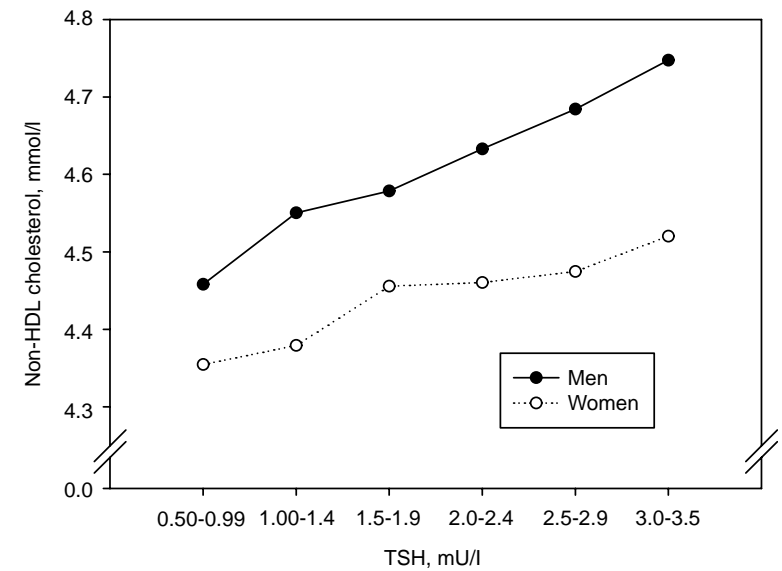

Figure 1 Geometric mean of non-HDL cholesterol by categories of TSH within the reference range $(0.50-3.5 \mathrm{mU} / \mathrm{l})$, in men $(n=9545)$ and women $(n=18182)$. Adjusted for age, smoking status and time since last meal. substantially influence these associations. The linearity of the associations of TSH with non-HDL cholesterol and HDL cholesterol is illustrated in Figs 1 and 2 respectively.

Subgroup analyses showed statistically significant associations for all lipids in men above 50 years of age and for triglycerides in all age groups. For women, associations were statistically significant in all age groups except for HDL cholesterol in women below 50 years of age. We explored whether the associations between TSH and serum lipids differed between overweight (BMI $25.0 \mathrm{~kg} / \mathrm{m}^{2}$ or higher) and normal weight (BMI lower than $25.0 \mathrm{~kg} / \mathrm{m}^{2}$ ) individuals. For total serum cholesterol, LDL cholesterol and non-HDL cholesterol, the results were similar between the groups.

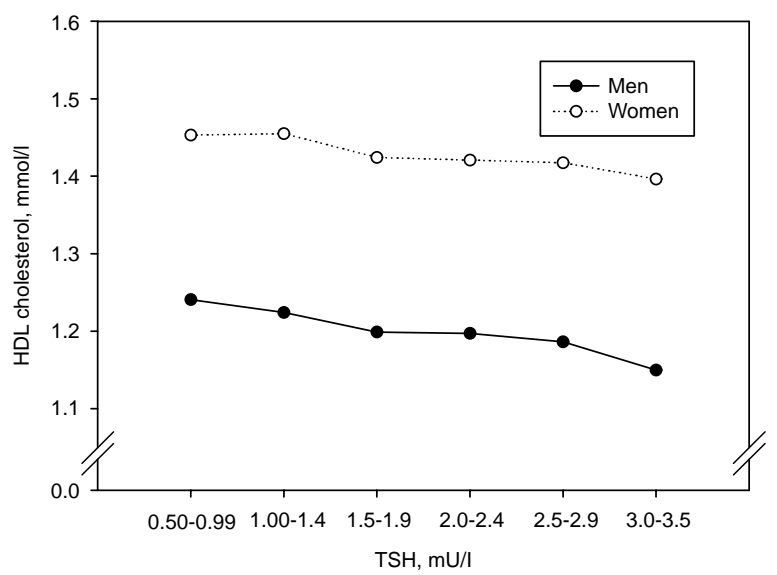

Figure 2 Geometric mean of HDL cholesterol by categories of TSH within the reference range $(0.50-3.5 \mathrm{mU} / \mathrm{l})$, in men $(n=9545)$ and women $(n=18182)$. Adjusted for age, smoking status and time since last meal. 
Table 2 Geometric mean of HDL cholesterol and triglycerides ( $\mathrm{mmol} / \mathrm{l})$ according to categories of thyroid stimulating hormone (TSH) within the reference range $(0.50-3.5 \mathrm{mU} / \mathrm{l})$, by sex and body mass index (BMI).

\begin{tabular}{|c|c|c|c|c|}
\hline \multirow[b]{2}{*}{$\begin{array}{l}\mathrm{BMI} \\
N\end{array}$} & \multicolumn{2}{|c|}{ Men } & \multicolumn{2}{|c|}{ Women } \\
\hline & $\begin{array}{c}<25.0 \mathrm{~kg} / \mathrm{m}^{2} \\
2964\end{array}$ & $\begin{array}{c}\geq 25.0 \mathrm{~kg} / \mathrm{m}^{2} \\
6522\end{array}$ & $\begin{array}{c}<25.0 \mathrm{~kg} / \mathrm{m}^{2} \\
6902\end{array}$ & $\begin{array}{c}\geq 25.0 \mathrm{~kg} / \mathrm{m}^{2} \\
11090\end{array}$ \\
\hline & \multicolumn{4}{|c|}{$H D L$ cholesterol $^{*}$} \\
\hline TSH (mU/l) & & & & \\
\hline $0.50-0.99$ & 1.35 & 1.19 & 1.62 & 1.39 \\
\hline $1.00-1.4$ & 1.33 & 1.18 & 1.64 & 1.39 \\
\hline $1.5-1.9$ & 1.31 & 1.16 & 1.60 & 1.36 \\
\hline $2.0-2.4$ & 1.34 & 1.15 & 1.62 & 1.35 \\
\hline $2.5-2.9$ & 1.34 & 1.14 & 1.62 & 1.35 \\
\hline $3.0-3.5$ & 1.36 & 1.09 & 1.59 & 1.34 \\
\hline$\%$ Change $(95 \% \mathrm{Cl})$ & $0.2(-1.4$ to 1.7$)$ & $-3.1(-4.0$ to -2.1$)$ & $-0.6(-1.5$ to 0.3$)$ & $-1.7(-2.4$ to -1.0$)$ \\
\hline \multirow[t]{2}{*}{$P$ for trend } & 0.843 & $<0.001$ & 0.226 & $<0.001$ \\
\hline & \multicolumn{4}{|c|}{ Triglycerides $^{\dagger}$} \\
\hline \multicolumn{5}{|l|}{ TSH (mU/l) } \\
\hline $0.50-0.99$ & 1.13 & 1.64 & 1.09 & 1.45 \\
\hline $1.00-1.4$ & 1.14 & 1.65 & 1.08 & 1.50 \\
\hline $1.5-1.9$ & 1.19 & 1.74 & 1.10 & 1.54 \\
\hline $2.0-2.4$ & 1.18 & 1.76 & 1.11 & 1.55 \\
\hline $2.5-2.9$ & 1.23 & 1.84 & 1.11 & 1.52 \\
\hline $3.0-3.5$ & 1.18 & 1.88 & 1.11 & 1.63 \\
\hline$\%$ Change $(95 \% \mathrm{Cl})$ & $3.5(0.7-6.3)$ & $6.0(4.0-7.9)$ & $1.0(-0.6$ to 2.6$)$ & $3.6(2.3-5.0)$ \\
\hline$P$ for trend & 0.015 & $<0.001$ & 0.223 & $<0.001$ \\
\hline
\end{tabular}

Adjusted for age, smoking status and time since last meal. \% Change: percentage change in serum lipids per $\mathrm{mU} / \mathrm{l}$ increase in TSH. ${ }^{\star} P$ for interaction between $\mathrm{TSH}$ and $\mathrm{BMI}<0.001$. ${ }^{\dagger} P$ for interaction between $\mathrm{TSH}$ and $\mathrm{BMI}=0.01$.

The positive association related to triglycerides was stronger among the overweight $(P$ for interaction $=$ $0.01)$, and the negative association between TSH and HDL cholesterol was observed only among overweight people ( $P$ for interaction $<0.001$; Table 2 ).

Table 3 shows the association between TSH and serum lipids, where TSH concentrations outside the reference range were included. The results showed consistent positive associations between TSH and concentrations of total serum cholesterol, LDL cholesterol, non-HDL cholesterol and triglycerides, but no clear association with HDL cholesterol. In the group that was defined as subclinically hypothyroid, concentrations of total serum cholesterol, LDL cholesterol,
non-HDL cholesterol and triglycerides were modestly elevated, when compared with those who were within the reference range of TSH $(P=0.005$ for triglycerides, $P<0.001$ for the other lipids).

\section{Discussion}

This large population-based study provides a unique opportunity to study the association between TSH and concentrations of serum lipids within the reference range of TSH. We found that total serum cholesterol, LDL cholesterol, non-HDL cholesterol and triglycerides increased consistently with increasing TSH and that

Table 3 Geometric mean of serum lipids (mmol/l) by categories of thyroid stimulating hormone (TSH), adjusted for sex, age, smoking status and time since last meal.

\begin{tabular}{|c|c|c|c|c|c|c|c|}
\hline $\begin{array}{l}\text { TSH (mU/l) } \\
N\end{array}$ & $\begin{array}{c}<0.10 \\
128\end{array}$ & $\begin{array}{c}0.10-0.49 \\
569\end{array}$ & $\begin{array}{c}0.50-3.5 \\
27727\end{array}$ & $\begin{array}{c}3.6-9.9 \\
2007\end{array}$ & $\begin{array}{l}\geq 10.0 \\
225\end{array}$ & $P$ for trend & $\begin{array}{c}\text { SH } \\
1247\end{array}$ \\
\hline $\begin{array}{l}\text { Total serum } \\
\text { cholesterol }\end{array}$ & 5.10 & 5.78 & 5.92 & 6.06 & 6.37 & $<0.001$ & 6.05 \\
\hline $95 \% \mathrm{Cl}$ & $4.93-5.27$ & $5.68-5.89$ & $5.86-5.98$ & $5.98-6.13$ & $6.21-6.54$ & & $5.96-6.13$ \\
\hline LDL cholesterol $^{\mathrm{a}}$ & 3.45 & 4.04 & 4.17 & 4.30 & 4.57 & $<0.001$ & 4.28 \\
\hline $95 \% \mathrm{Cl}$ & $3.30-3.62$ & $3.94-4.14$ & $4.11-4.23$ & $4.22-4.37$ & $4.40-4.74$ & & $4.19-4.37$ \\
\hline $\begin{array}{l}\text { Non-HDL } \\
\text { cholesterol }\end{array}$ & 3.70 & 4.36 & 4.51 & 4.66 & 4.96 & $<0.001$ & 4.64 \\
\hline $95 \% \mathrm{Cl}$ & $3.53-3.87$ & $4.25-4.47$ & $4.44-4.57$ & $4.57-4.74$ & $4.78-5.14$ & & $4.55-4.74$ \\
\hline HDL cholesterol & 1.27 & 1.33 & 1.31 & 1.29 & 1.31 & 0.051 & 1.29 \\
\hline $95 \% \mathrm{Cl}$ & $1.21-1.33$ & $1.29-1.36$ & $1.29-1.33$ & $1.26-1.31$ & $1.26-1.36$ & & $1.26-1.32$ \\
\hline Triglycerides & 1.36 & 1.43 & 1.47 & 1.56 & 1.61 & $<0.001$ & 1.53 \\
\hline $95 \% \mathrm{Cl}$ & $1.24-1.50$ & $1.36-1.50$ & $1.43-1.51$ & $1.50-1.61$ & $1.50-1.73$ & & $1.47-1.59$ \\
\hline
\end{tabular}

$\mathrm{SH}$, subclinical hypothyroidism, defined by TSH 4.1-9.9 mU/l combined with free thyroxine of $8.0 \mathrm{pmol} / \mathrm{l}$ or higher.

aLDL cholesterol was calculated only if serum triglyceride concentrations were lower than $4.5 \mathrm{mmol} / \mathrm{l}$. 
HDL decreased consistently. These associations displayed remarkably linear trends, with no indication for any threshold effects.

Our data appear to confirm the results of some small studies of TSH among people with no apparent thyroid dysfunction. These studies showed positive associations with total serum cholesterol (8) and LDL cholesterol (9), and a negative association with HDL cholesterol (9).

There appears to be a consensus that many people with TSH in the upper part of the reference range are likely to display early signs of thyroid dysfunction (15). Results from 20 years of follow-up of the Whickham Study indicated that TSH higher than $2 \mathrm{mU} / \mathrm{l}$ was associated with increased risk of hypothyroidism (16). Previous studies among euthyroid people have found that the prevalence of thyroid peroxidase antibodies, indicating autoimmune thyroid disease, increases with increasing level of TSH $(10,12,15)$. In our study, there was a linear increase in serum lipids, with no apparent increase in the uppermost part of the reference range. Although we cannot exclude the possibility that TSH is more strongly associated with serum lipids in people with subtle signs of autoimmune thyroid disease, our results suggest that the association with serum lipids is present across the range of TSH that is considered clinically normal.

Whereas triglyceride concentrations are sensitive to eating, cholesterol levels are less affected (17). In the analyses, we adjusted for time since last meal to account for daily fluctuations in lipid concentrations, but these adjustments did not substantially influence the estimates. However, there is also diurnal variation in serum TSH, with relatively higher levels in the morning than later in the day (15). Whether these variations may influence the association between TSH and serum lipids, is not clear.

High levels of triglycerides are often accompanied by low HDL cholesterol, especially in insulin-resistant individuals. A possible mechanism is that HDL particles associated with high triglyceride concentrations may be more readily catabolised (18). We observed that the association between TSH and HDL cholesterol among overweight individuals was substantially attenuated after adjustment for triglyceride level. This may suggest that the negative association between TSH and HDL cholesterol, at least in part, may be mediated by relatively high triglyceride concentrations.

Studies of lipid metabolism related to thyroid dysfunction may provide some understanding of mechanisms that could underlie the consistent associations in our study. Thus, high total serum cholesterol and LDL cholesterol may be caused by fewer cell-surface receptors for $\mathrm{LDL}$, resulting in reduced LDL catabolism (2). For triglycerides, reduced activity of lipoprotein lipase $(19,20)$, or impaired clearance of lipoproteins dependent on LDL receptor function (21), may result in higher levels. However, it should be acknowledged that studies of lipid metabolism related to thyroid dysfunction may not be relevant to explain our findings within the normal range of thyroid function.

These data show linear positive associations between TSH in the reference range and concentrations of total serum cholesterol, LDL cholesterol, non-HDL cholesterol and triglycerides, and a linear negative association with HDL cholesterol. Thus, TSH levels indicating clinically normal thyroid function may have long-term harmful effects on cardiovascular health through the association with serum lipids. However, the strengths of the associations were modest, and their clinical significance remains to be determined in prospective studies of variations in normal thyroid function related to risk of cardiovascular disease.

\section{Acknowledgements}

The study was financially supported by the Norwegian University of Science and Technology and by the Central Norway Regional Health Authority. The HUNT Research Centre provided the data. A special thanks to the Hormone Laboratory, Aker University Hospital, Oslo that analysed all thyroid function tests with some financial support from Wallac Oy, Turku, Finland. Contributors: BOÅ conceived the idea, did the analyses and wrote the paper. TB was responsible for designing the original sub-study of thyroid function within the HUNT Study, and designed and participated in the writing of the present study. TILN participated in the statistical analyses and interpretation of the results. LJV participated in the analyses, interpreted the results and wrote the paper.

\section{References}

1 Duntas LH. Thyroid disease and lipids. Thyroid 200212 287-293.

2 Cappola AR \& Ladenson PW. Hypothyroidism and atherosclerosis. Journal of Clinical Endocrinology and Metabolism $2003 \mathbf{8 8}$ 2438-2444.

3 Canaris GJ, Manowitz NR, Mayor G \& Ridgway EC. The Colorado thyroid disease prevalence study. Archives of Internal Medicine 2000 $160526-534$.

4 Surks MI, Ortiz E, Daniels GH, Sawin CT, Col NF, Cobin RH, Franklyn JA, Hershman JM, Burman KD, Denke MA, Gorman C, Cooper RS \& Weissman NJ. Subclinical thyroid disease: scientific review and guidelines for diagnosis and management. Journal of the American Medical Association 2004291 228-238.

5 Danese MD, Ladenson PW, Meinert CL \& Powe NR. Clinical review 115: effect of thyroxine therapy on serum lipoproteins in patients with mild thyroid failure: a quantitative review of the literature. Journal of Clinical Endocrinology and Metabolism $2000 \mathbf{8 5}$ 2993-3001.

6 Meier C, Staub JJ, Roth CB, Guglielmetti M, Kunz M, Miserez AR, Drewe J, Huber P, Herzog R \& Muller B. TSH-controlled L-thyroxine therapy reduces cholesterol levels and clinical symptoms in subclinical hypothyroidism: a double blind, placebo-controlled trial (Basel Thyroid Study). Journal of Clinical Endocrinology and Metabolism 200186 4860-4866.

7 Iqbal A, Jorde R \& Figenschau Y. Serum lipid levels in relation to serum thyroid-stimulating hormone and the effect of thyroxine 
treatment on serum lipid levels in subjects with subclinical hypothyroidism: the Tromso Study. Journal of Internal Medicine $200626053-61$.

8 Pallas D, Koutras DA, Adamopoulos P, Marafelia P, Souvatzoglou A, Piperingos G \& Moulopoulos SD. Increased mean serum thyrotropin in apparently euthyroid hypercholesterolemic patients: does it mean occult hypothyroidism? Journal of Endocrinological Investigation 1991 $14743-746$.

9 Bakker SJ, ter Maaten JC, Popp-Snijders C, Slaets JP, Heine RJ \& Gans RO. The relationship between thyrotropin and low density lipoprotein cholesterol is modified by insulin sensitivity in healthy euthyroid subjects. Journal of Clinical Endocrinology and Metabolism 200186 1206-1211.

10 Michalopoulou G, Alevizaki M, Piperingos G, Mitsibounas D, Mantzos E, Adamopoulos P \& Koutras DA. High serum cholesterol levels in persons with 'high-normal' TSH levels: should one extend the definition of subclinical hypothyroidism? European Journal of Endocrinology 1998138 141-145.

11 Holmen J, Midthjell K, Kruger O, Langhammer A, Holmen TL, Bratberg GH, Vatten LJ \& Lund-Larsen PG. The Nord-Trøndelag Health Study 1995-97 (HUNT 2): objectives, contents, methods and participation. Norsk Epidemiologi 200313 19-32.

12 Bjoro T, Holmen J. Kruger O, Midthjell K, Hunstad K, Schreiner T, Sandnes L \& Brochmann H. Prevalence of thyroid disease, thyroid dysfunction and thyroid peroxidase antibodies in a large, unselected population. The Health Study of Nord-Trondelag (HUNT). European Journal of Endocrinology 2000143 639-647.

13 Friedewald WT, Levy RI \& Fredrickson DS. Estimation of the concentration of low-density lipoprotein cholesterol in plasma, without use of the preparative ultracentrifuge. Clinical Chemistry $197218499-502$.

14 Packard CJ \& Saito Y. Non-HDL cholesterol as a measure of atherosclerotic risk. Journal of Atherosclerosis and Thrombosis 2004 11 6-14.
15 Surks MI, Goswami G \& Daniels GH. The thyrotropin reference range should remain unchanged. Journal of Clinical Endocrinology and Metabolism 200590 5489-5496.

16 Vanderpump MPJ, Tunbridge WMG, French JM, Appleton D, Bates D, Clark F, Grimley Evans J, Hasan DM, Rodgers H, Tunbridge F \& Young ET. The incidence of thyroid disorders in the community: a twenty-year follow-up of the Whickham Survey. Clinical Endocrinology (Oxf) 199543 55-68.

17 Craig SR, Amin RV, Russell DW \& Paradise NF. Blood cholesterol screening influence of fasting state on cholesterol results and management decisions. Journal of General Internal Medicine 2000 15 395-399.

18 Rashid S, Watanabe T, Sakaue T \& Lewis GF. Mechanisms of HDL lowering in insulin resistant, hypertriglyceridemic states: the combined effect of HDL triglyceride enrichment and elevated hepatic lipase activity. Clinical Biochemistry $200336421-429$.

19 Lithell H, Boberg J, Hellsing K, Ljunghall S, Lundqvist G, Vessby B \& Wide L. Serum lipoprotein and apolipoprotein concentrations and tissue lipoprotein-lipase activity in overt and subclinical hypothyroidism: the effect of substitution therapy. European Journal of Clinical Investigation 198111 3-10.

20 Pykalisto O, Goldberg AP \& Brunzell JD. Reversal of decreased human adipose tissue lipoprotein lipase and hypertriglyceridemia after treatment of hypothyroidism. Journal of Clinical Endocrinology and Metabolism 197643 591-600.

21 Liu XQ, Rahman A, Bagdade JD, Alaupovic P \& Kannan CR. Effect of thyroid hormone on plasma apolipoproteins and apoA- and apoB-containing lipoprotein particles. European Journal of Clinical Investigation $1998 \mathbf{2 8} 266-270$.

Received 2 August 2006

Accepted 10 November 2006 